\title{
Sensing acidosis: nociception or sngception?
}

\author{
Jiann-Her Lin ${ }^{1,2+}{ }^{\text {, Chih-Hsien Hung }}{ }^{1,3,4 \dagger}$, Der-Sheng Han ${ }^{5 \dagger}$, Shih-Ting Chen ${ }^{1}$, Cheng-Han Lee ${ }^{1}$, Wei-Zen Sun ${ }^{6 *}$ \\ and Chih-Cheng Chen ${ }^{1,4,7^{*}}$ (D)
}

\begin{abstract}
Background: Sensing tissue acidosis is an important function of the somatosensory nervous system to response to noxious stimuli.

Main body: In the pain clinic, acid or soreness sensation is a characteristic sensory phenotype of various acute and chronic pain syndromes, such as delayed onset muscle soreness, fibromyalgia, and radicular pain. However, soreness sensation is a sign of successful analgesia for acupuncture and noxipoint therapy. Thus, the nature of acid or soreness sensation is not always nociceptive (or painful) and could be anti-nociceptive. To facilitate the investigation of the molecular and neurobiological mechanisms of soreness sensation, we propose a concept called "sngception (sng-ception)" to describe the response of the somatosensory nervous system to sense tissue acidosis and to distinguish it from nociception. "Sng" is a Taiwanese word that represents the state of soreness while at the same time imitates the natural vocalization of humans feeling sore.

Conclusion: Here we propose sngception as a specific somatosensory function that transmits the acid sensation from the peripheral to the central nervous system. Sngception could partially overlap with nociception, but it could also transmit antinociception, proprioception, and pruriception.
\end{abstract}

Keywords: Acidosis, ASIC3, Nociception, Pain, Sngception, Soreness

\section{Introduction}

Tissue acidosis is a physiological or pathological phenomenon occurring during tissue injury, inflammation, ischemia, fatiguing exercise, and tumor growth [15]. Clinically, several types of acute and/or chronic pain are closely associated with tissue acidosis ranging from pH 7.3 to 5.8 or lower (Table 1). Thus, sensing tissue acidosis is an important function for the somatosensory nervous system to monitor and respond to the "noxious" stimulation.

Somatosensory nerves projected from dorsal root ganglia (DRG), trigeminal ganglia (TG), nodose ganglia, etc. are responsible for detecting such noxious acidosis [6]. Many ion channels and receptors have been identified as

\footnotetext{
* Correspondence: wzsun@ntu.edu.tw; chih@ibms.sinica.edu.tw

${ }^{\dagger}$ Jiann-Her Lin, Chih-Hsien Hung and Der-Sheng Han contributed equally to this work.

${ }^{6}$ Department of Anesthesiology, National Taiwan University Hospital, Taipei, Taiwan

'Institute of Biomedical Sciences, Academia Sinica, 128 Academia Rd. Sec. 2, Taipei 115, Taiwan

Full list of author information is available at the end of the article
}

proton-sensing receptors expressing in a variety of sensory neurons, including the pain-sensing fibers or "nociceptors". To probe how acidosis is sensed in the somatosensory nervous system, techniques involving whole-cell patch clamp recordings of dissociated neurons are commonly used [7]. Many efforts have involved demonstrating that acidosis can effectively induce inward currents in nociceptive neurons of DRG and TG and thus depolarize the neurons to transmit the noxious acid signals to the brain where we feel the pain. Combined with the retrograde tracing technique, whole-cell patch clamp recordings have thus revealed that acid-sensitive sensory neurons innervate tissues all over the body, including skin, muscle, joint, bone, tooth, intestine, colon, and many viscera tissues $[6,8]$.

\section{Proton-sensing molecules in nociceptors}

Experimentally, intradermal or intramuscular acidosis is noxious and painful in humans [9-12]. However, the exact acid sensors in the nociceptors that trigger pain are still disputed. Candidate proton-sensing ion channels 
Table 1 Types of tissue acidosis and associated pain

\begin{tabular}{|c|c|c|c|c|c|}
\hline Conditions & Affected sites & Examples & $\mathrm{pH}$ ranges (in animal models) & Pain/soreness & References \\
\hline \multirow[t]{7}{*}{ Ischemia } & Brain & Stroke & $6.2 \sim 7.0$ (Rat) & Central post-stroke pain & {$[47]$} \\
\hline & Brain & Intracranial hypertension & $\sim 7.05$ & Headache and widespread pain & {$[48,49]$} \\
\hline & Heart & Angina & $6.9 \sim 7.0$ (Cat) & Chest pain & [4] \\
\hline & Intestine & Small bowel obstruction & $6.8 \sim 7.1$ & Abdominal pain & [50] \\
\hline & Lower limbs & Peripheral artery disease & $<7.15$ (Cat) & Pain & [51] \\
\hline & Muscle & Tourniquet test & $\sim 7.0$ & Muscle pain & [9] \\
\hline & Vessel & Sickle cell disease & $<7.36$ & Sickle pain & {$[52,53]$} \\
\hline \multirow[t]{2}{*}{ Injury } & Skin & Surgery & 6.9 7.1 (Rat) & Postoperative pain & {$[5]$} \\
\hline & Muscle & Surgery & $6.5 \sim 7.1$ (Rat) & Postoperative pain & {$[5]$} \\
\hline \multirow[t]{5}{*}{ Inflammation } & Joint & Osteoarthritis & $6.9 \sim 7.4$ (Rabbit) & Pain & {$[54]$} \\
\hline & Joint & Rheumatoid arthritis & $\begin{array}{l}7.1 \sim 7.4 \\
\sim 6.2 \text { (Mouse) }\end{array}$ & Pain & $\begin{array}{l}{[34]} \\
{[3]}\end{array}$ \\
\hline & Skin & Skin wound & 7.0 7.3 (Rabbit) & Dermal pain & {$[55]$} \\
\hline & Blood & Sepsis & $7.2 \sim 7.3$ & Pain/Soreness & {$[56]$} \\
\hline & Muscle & Flu & NA & Pain/soreness & {$[57]$} \\
\hline Fatiguing exercise & Muscle & Delayed onset muscle soreness & $6.6 \sim 6.9$ (Mouse) & Soreness & [2] \\
\hline \multirow[t]{2}{*}{ Metabolism disorders } & Blood & Diabetic ketoacidosis & $\leq 6.9 \sim 7.2$ & Abdominal pain & {$[58]$} \\
\hline & Blood & Renal tubular acidosis & $\sim 7.2$ & Widespread muscle \& joint pain & {$[59]$} \\
\hline Tumor & Bone & Bone cancer & $4.0 \sim 6.0$ (Mouse) & Cancer pain & {$[60]$} \\
\hline
\end{tabular}

and/or receptors contributing to acid-induced pain include members of acid-sensing ion channels (ASICs), transient receptor potential (TRP) channels, protonsensing G-protein-coupled receptors (e.g., GPR4, G2A, OGR1, TDAG8), and two pore potassium channels
(K2Ps) (Fig. 1) [13]. Among these proton-sensing membrane proteins, ASIC3 and TRP/vanilloid receptor subtype 1 (TRPV1) are most abundantly expressed in nociceptors and thus are intensely studied for their roles in acid-induced pain in humans and animals. In rodents,

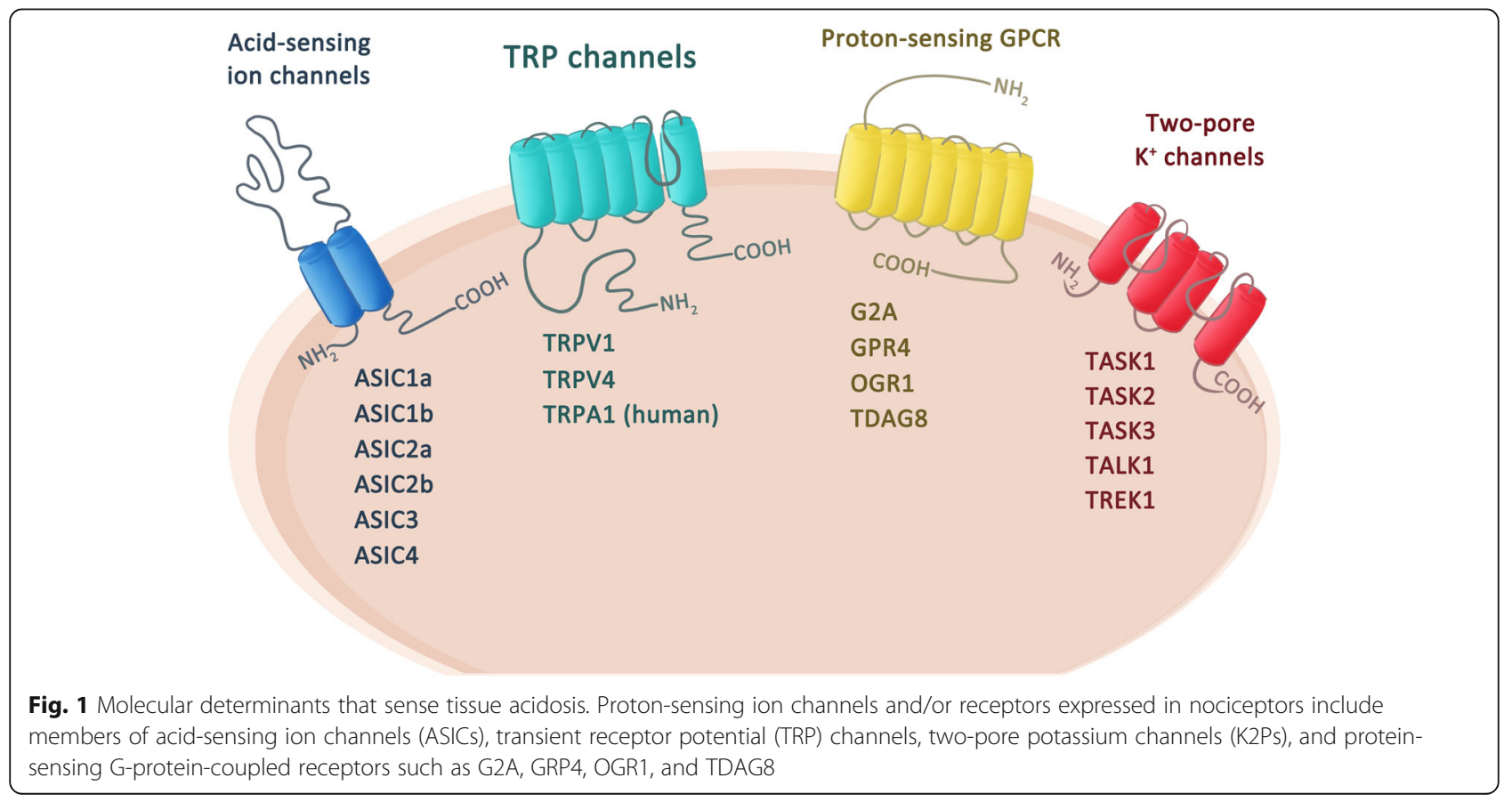


pharmacological blockade or genetic deletion of ASIC3 prevents the induction of pain behaviors in models of postoperative pain, inflammatory pain, and ischemic pain [14]. In a mouse model of fibromyalgia induced by repeated intramuscular acid injections, ASIC3 and TRPV1 play essential roles in acute pain induction, hyperalgesic priming, and the development of chronic pain $[15,16]$.

\section{Does acid induce nociception or sngception?}

Although accumulating evidence has shown that acid can induce nociception and trigger pain, researchers in the field of pain biology or neuroscience have oversimplified the roles of acid sensation for decades. For instance, since the earliest discovery of acid-induced currents in sensory neurons, researchers have identified the proton-activated conductance in a variety of sensory neuron subtypes including nociceptors and non-nociceptors [17]. The discovery was initiated by an original assumption: "pH is one of the most stable parameters of homeostasis - why shouldn't there be a quick neuronal sensor capable of transforming this parameter into the receptor potential and sensory code?" [18]. Later studies found acid-induced currents in $\sim 67 \%$ of total DRG neurons, which is much higher than the total number of nociceptors [7]. In particular, $85 \%$ of muscle afferent DRG neurons are acid-sensitive [15]. Obviously, many acid-sensitive DRG neurons are not nociceptors, whereas many nociceptors are not acid-sensitive $[15,19]$. In knockout mouse models, lacking an ASIC subtype produces defects in acidosis-induced pain and in neurosensory mechanotransduction $[6,19]$. Therefore, acid sensation cannot be included with nociception, although overlap does exist.

In clinical practice, acid sensation might be related to soreness sensation, as shown in delayed-onset muscle soreness (DOMS) [20]. Many types of pain disorders are closely related to tissue acidosis (Table 1 ). In addition, acidosis induced itchiness or paresthesia in many clinical studies of health volunteers [11, 21]. Moreover, experienced clinicians usually depend on inquiring about a patient's soreness sensation as a crucial sign of whether the correct manipulation of the targeted acupoint and noxipoint is reached [22, 23]. Thus, to interpret the multiple roles of acid sensation involved in nociception, anti-nociception, and non-nociceptive sensation, we propose "sngception" to replace "nociception" to describe acid sensation and/or soreness sensation in the somatosensory system (Table 2). Briefly, "sng" is a Taiwanese word that represents the state of soreness while at the same time imitates the natural vocalization of humans feeling sore.

\section{Acid-mediated nociception and anti-nociception}

Accumulating evidence has shown ASIC3 and TRPV1 as two major acid sensors in nociceptors that trigger acid-induced pain in mouse models of fibromyalgia [13, 15]. However, our recent studies have shown that acid can also mediate an anti-nociceptive effect on muscle nociceptors while both ASIC3 and TRPV1 are blocked [24]. We name this acid-mediated anti-nociception non-ASIC, non-TRPV1 acid signaling, which involves the release of substance $\mathrm{P}$ from muscle afferent terminals and acts on NK1R to open an M-type potassium channel (Kv7) in a G-protein-independent, tyrosine kinase-dependent manner [25]. The acid-mediated anti-nociception can tune the acid-induced nociceptor priming and thus prevent pain chronicity in fibromyalgia models [13]. Interestingly, about $\sim 60 \%$ of acid-sensitive muscle afferent DRG neurons express neither ASIC3 nor TRPV1 [15]. The molecular identity of the non-ASIC3, non-TRPV1 acid sensor is not known, but possible candidates are proton-sensing receptors and/or ion channels expressed in muscle afferents, including GRP4, G2A, OGR1, TDAG8, ASIC1a, ASIC1b, ASIC2a, ASIC2b, TRPA1, TASK1 3, and TREK1 (Fig. 1).

The acid-mediated anti-nociceptive effect reminds us of a specific soreness sensation, also called De-qi (得氣), occurring in acupuncture analgesia [23]. Similarly, soreness sensation is a key factor of a novel noxipoint therapy to treat chronic neck and shoulder pain, in which analgesia can be achieved via intense electrical shock on two ends of a muscle to trigger a soreness sensation [22]. In both cases, the soreness sensation of deep tissues is a sign of anti-nociception, which may be related to the

Table 2 The phenomena of pain and sng

\begin{tabular}{lll}
\hline & Pain & Sng \\
\hline Trigger & Tissue damage & Tissue acidosis; \\
& & mechanical stimuli \\
Sensation & Nociception & Sngception \\
Perception & Pain & Soreness (or Sng) \\
Responses & Suffering & Suffering; relief by passive massage and/or active stretch \\
Behaviors & Avoiding & Dual manifestations: \\
& & (1) avoiding; \\
& & (2) active relieving maneuvers (e.g., hitting, stretch, massage).
\end{tabular}


non-ASIC3, non-TRPV1 acid signaling, although it might be also nociceptive. In one-third of fibromyalgia patients who have prominent soreness phenotypes, acupuncture usually has no analgesic effect and even worsens the soreness phenotypes. Thus, here we propose that the soreness phenotype of fibromyalgia is an imbalanced acid signaling between acid-induced nociception and acid-mediated anti-nociception, mainly due to impaired non-ASIC3, non-TRPV1 acid signaling (Fig. 2). In contrast, acupuncture, noxipoint therapy, or aerobic/ muscular endurance training could boost the antinociceptive acid (soreness) signaling and thus relieve pain. In sport medicine, well-trained athletes can tolerate exercise-induced muscle damage (EIMD) and muscle soreness. EIMD is scientifically and clinically accepted as an important phenomenon in sport medicine, but soreness is usually considered the primary endpoint for proper recovery from the "damage" [26]. Thus, professional coaches and athletes would develop active strengthening programs to adapt to the "soreness" and speed up the recovery process.

Although the non-ASIC3, non-TRPV1 acid sensor is a promising novel target for the development of effective analgesics, its molecular identity is not known. Thus, probing the molecular determinants that contribute to the non-ASIC3, non-TRPV1 acid signaling will be a key step to reveal the mystery of fibromyalgia, especially for individuals who have soreness phenotypes and are resistant to acupuncture analgesia.

Hence, sngception could be nociception mediated by ASIC3 and/or TRPV1 or anti-nociception mediated by non-ASIC3, non-TRPV1 acid sensors.

\section{Non-nociceptive acid sensation}

Besides nociception and anti-nociception, acidic citric buffer (pH 3.0) induces itch responses in mouse skin and histamine-sensitized skin in humans [21]. Itch sensation is mediated by a group of somatosensory neurons named pruriceptors that express specific types of G-protein-coupled receptors (such as H1, MRGPRX1, MRGPRA3, etc.), and/or a TRP channel, (TRPV1 or TRPA1), or a mechanoreceptor responding to pruritic agents including histamine, chloroquine, serotonin, heat, mechanical stimuli, etc. [27]. Based on these findings, itch sensation can be conducted by pruriceptors based on the specificity model, by which there are peripheral sensory neurons solely activated by pruritive stimuli so that itch can be decoded in the brain following a labeled line pathway. However, since these pruriceptive neurons also express transducers that respond to noxious stimuli (e.g., TRPV1 and TRPA1), there are several models (including opponent theory, pattern theory, intensity/temporal theory, and spatial contrast theory) to reconcile contradictory findings of

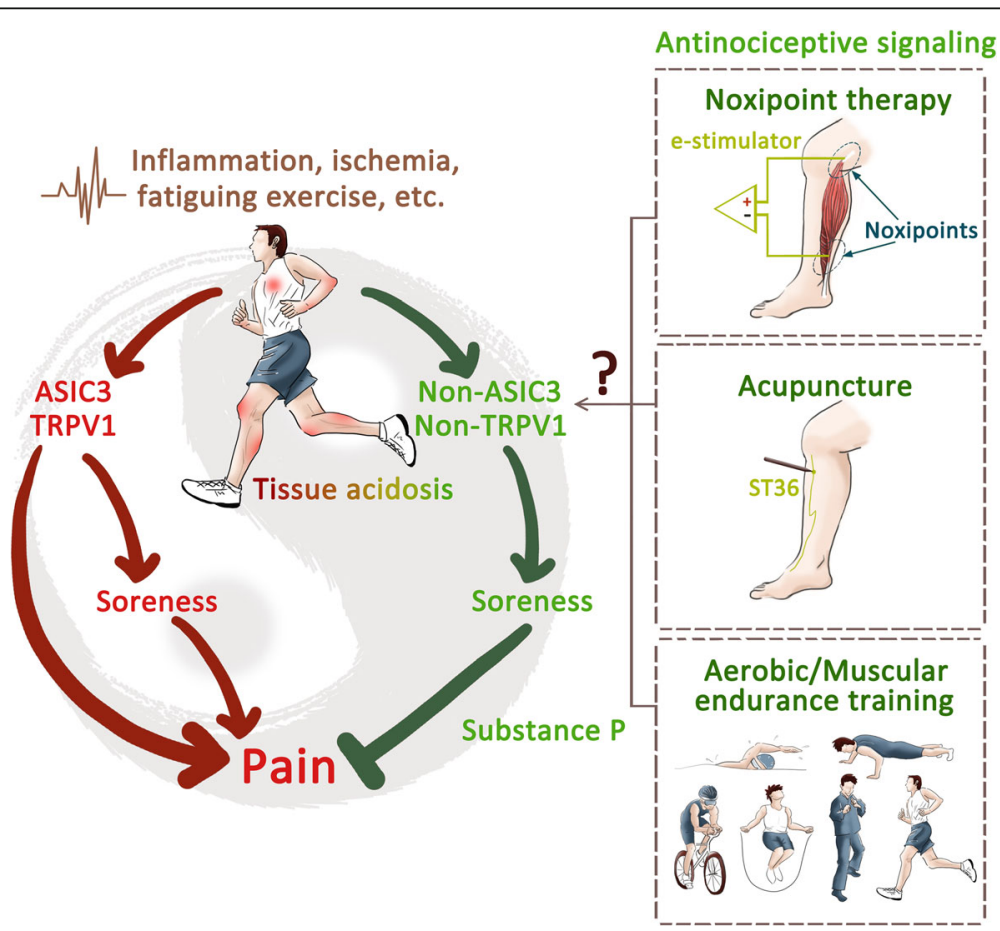

Fig. 2 Soreness hypothesis. Tissue acidosis simultaneously evokes a pro-nociceptive signaling via ASIC3/TRPV1 activation and an anti-nociception via non-ASIC3, non-TRPV1 acid signaling. In most cases, pain associated with tissue acidosis is the balanced result of pro-nociceptive and anti-nociceptive acid signaling. In physical therapy, soreness sensation induced by acupuncture and/or noxipoint therapy is a sign of successful analgesia to balance the pro-nociceptive signaling. Fibromyalgia patients might have soreness phenotypes due to an imbalance of acid signaling in muscle nociceptors, especially with impaired non-ASIC3, non-TRPV1 acid signaling 
itch and pain studies [28-30]. The noxious acidosis-induced itch responses are mediated by TRPV1 and TDAG8 [31]. Because TDGA8 is more sensitive to acid than TRPV1, the acidosis-induced itch could fit in the spatial contrast theory, which states that itch arises from a sharp contrast between individual nociceptors firing among the surrounding silent neighbors [30]. In the context of skin acidosis, protons could be gradually diffused in the local tissue and assumed to simultaneously activate a wide range of acid-sensitive neurons, so that acid could evoke sharp contrast activation of afferents with TDAG8-TRPV1 coupling among TRPV1-positive/ TDAG8-negative afferents.

Moreover, recent studies have shown ASIC3 involved in mechanotransduction of DRG proprioceptors, the low-threshold mechanoreceptors responding to force changes during muscle contraction [32]. In DRG proprioceptors, the mechanically activated currents induced by neurite stretching are largely inhibited by the ASIC3-selective antagonist APETx2 or ASIC3 gene knockout. Surprisingly, although proprioceptors are well-characterized mechanoreceptors, ASIC3 mediates an acid-induced inward current in DRG proprioceptors similar to that found in DRG nociceptors. ASIC3 was found to be a dual-function protein involved in both acid-sensing and mechano-sensing in proprioceptors, although the role of acid-sensation in proprioceptors is unknown [33].

Thus, sngception also includes TDAG8- and TRPV1mediated itch sensation (or pruriception) and ASIC3-mediated proprioception.

\section{Sngception in the context of chronic pain}

In clinical observations, diverse somatic complaints exist among different pain conditions. For instance, DOMS usually leads to characteristic pain-related phenotypes (e.g., hyperalgesia and allodynia) and on-going muscle soreness that results in avoidance behaviors similar to those with other types of chronic pain. Mechanistically, the activation of TRPV1-, TRPV4-, and ASIC-positive afferents is essentially involved in the induction of DOMS [20]. In inflammatory musculoskeletal pain disorders, tissue acidosis is prominent and highly associated with disease severity [34, 35]. Take rheumatoid arthritis (RA) as an example, a number of studies have shown the conditions of tissue acidosis in synovial fluid is associated with inflammatory activity and disease severity [36, 37]. Studies of RA animal models have revealed tissue acidosis inflicted by inflammation would lead to activation and up-regulation of ASIC3 on nociceptive afferents, resulting in central sensitization and pain aggravation [38, 39]. Besides, TRPV1 and TDAG8 are involved in RA-associated inflammation and RA-induced hyperalgesia in animal models [40]. Unfortunately, we know little about whether soreness is also a prominent phenotype in RA patients, although muscle soreness is reported in $24 \%$ of patients with paraneoplastic rheumatic syndromes [41]. In the majority of cases, sngception is commonly overwhelmed by co-existing nociception and thus becomes relatively less distinct. However, in our experience, soreness (or sng) is a predominant sensory phenotype in patients with fibromyalgia and radiculopathy. In our series, soreness is not only one of the major complaints in lumbar stenosis-related low back pain, but also is one of the major reasons for surgical intervention because current treatment for soreness is unsatisfactory [42]. Therefore, soreness can be another major component in chronic pain disorders but is not yet valued.

Unfortunately, we know little about sngception in the chronic pain context. Future perspective studies are warranted to assess the clinical impacts of sngception on related diseases and to evaluate their responses to therapy. Tailored clinical tools for sngception (e.g., soreness questionnaire) are needed for clinical research of these pain disorders. In addition, research into the molecular and neurobiological basis of sngception in animal models will greatly advance our understanding of the chronicity of intractable pain (and soreness) and facilitate the development of better therapeutic strategies. Because sng (soreness) is a subjective perception and can be only reported from humans, translational studies with a reverse design from the clinic to animals are imperative for phenotype elucidation and identification.

\section{Concluding remarks}

Here we propose sngception as a specific somatosensory function that transmits the acid sensation from the peripheral to the central nervous system. Sngception could partially overlap with nociception, but it also transmits anti-nociception, proprioception, and pruriception mediated via different acid-sensitive receptors/ion channels and/or neurons with varied $\mathrm{pH}$ sensitivities. Similar to nociception, which can be sub-grouped into thermo-, mechano- and chemo-nociception, sngception is also composed of different sensory modalities. Further research is needed to delineate the sngception subtypes and underlying molecular mechanisms, as well as clinical impacts of sngception.

\section{Table 2: Nociception and sngception}

In the Chinese language, "sng(acid)-pain" (疼痛), meaning a combination of soreness and pain, is much more commonly reported than "pain" among patients with chronic pain, especially for those with musculoskeletal pain. In the English dictionary, soreness means the quality of being painful and uncomfortable because of injury or too much use. However, in pain clinics, delayed-onset muscle soreness (DOMS) is probably the only type of pain that clearly highlights "soreness" occurring a few 
days after fatiguing exercise. DOMS results in mechanical hyperalgesia, tenderness, and movement-related muscle ache (or soreness) that lead to avoiding behaviors as with other types of chronic pain. In addition, DOMS patients show compensatory behaviors (e.g., decreased proprioception and range of motion) in response to muscle soreness, which are symptoms distinguishable from other chronic pain [43]. In other aspects, soreness sensation is commonly described in patients with chronic pain during physical therapeutic procedures, such as acupuncture and noxipoint therapy, and is a sign of De-qi (specific for acupuncture) or successful analgesia [22, 23]. Because the soreness (or acid) sensation in not always painful, it should be defined as a way to distinguish it from nociception.

We introduce the term "sngception" specifically to describe the response of the somatosensory nervous system to sense tissue acidosis or the activation of acid-sensitive afferent neurons. "Sng" is a Taiwanese (Southern Min) word that represents the state of soreness while at the same time imitates the natural vocalization of humans feeling sore. The word first received its Romanization form by Dutch missionaries in the 1600s and was later established by Taiwanese Language Phonetic Alphabet and the Ministry of Education of Taiwan in the early twenty-first century [44]. Starting with a voiceless alveolar fricative-" $s$ " and a nasal velar sonorant -"ng" followed, "sng" delicately elicits the uniqueness of soreness apart from pain. In view of the importance of research into the sense of soreness, we introduce the term "sngception", the perception of sng, for the convenience of further investigation.

\section{Is there a place for soreness (sng) in pain taxonomy?}

Pain is "an unpleasant sensory and emotional experience associated with actual or potential tissue damage, and described in terms of such damage" as defined by the International Association for the Study of Pain [45]. To have a better understanding of pain, Loeser described the phenomena of pain as composed of nociception, pain, suffering, and pain behaviors, with nociception being the detection of potential tissue damage by the peripheral sensory system, perception of pain resulting from a noxious input to the central nervous system, suffering a negative response caused by perceiving pain, and pain behavior anything that a person tends to do or avoid doing as a result of suffering from pain and can be measured [46]. However, there is no place for "soreness" or "sng" in the current pain taxonomy.

Is "sng" composed of different phenomena from "pain"? From our daily life experience and/or clinical observation, we propose that the phenomena of "sng" might be composed of sngception, soreness (sng), suffering (or desire for massage), and sng behaviors, with sngception being the detection of tissue acidosis (or mechanical stimulus in acupuncture) by the peripheral sensory system; sng behaviors are anything a person tends to do to compensate for suffering from "sng". We summarize the comparison between "pain" and "sng" in Table 2.

\section{Abbreviations}

ASIC3: Acid-sensing ion channel 3; DOMS: Delayed onset muscle soreness; DRG: Dorsal root ganglion; EIMD: Exercise-induced muscle damage;

TG: Trigeminal ganglion; TRP: Transient receptor potential; TRPV1: TRP vanilloid receptor subtype 1

\section{Acknowledgements}

We thank Miss Chia-Wen Wong for her assistance in scientific illustration.

\section{Funding}

This work was supported by a grant from the Institute of Biomedical Sciences, Academia Sinica (IBMS-CRC107-P01) and grants from Ministry of Sciences and Technology, Taiwan (MOST105-2320-B-001-018-MY3, MOST107-2319-B-001-002, and MOST107-2321-B-001-020).

Availability of data and materials

Not applicable.

\section{Authors' contributions}

$J \mathrm{HL}, \mathrm{WZS}$, and CCC composed the idea and wrote the manuscript. JHL, CHH, DSH, CHL were involved in preparing the Table content. STC designed the terminology of sngception. All authors read and approved the final manuscript.

\section{Ethics approval and consent to participate}

Not applicable.

\section{Consent for publication}

Not applicable.

\section{Competing interests}

The authors declare that they have no competing interests.

\section{Publisher's Note}

Springer Nature remains neutral with regard to jurisdictional claims in published maps and institutional affiliations.

\section{Author details}

${ }^{1}$ Institute of Biomedical Sciences, Academia Sinica, 128 Academia Rd. Sec. 2, Taipei 115, Taiwan. ${ }^{2}$ Department of Neurosurgery, Taipei Medical University Hospital, Taipei, Taiwan. ${ }^{3}$ Department of Neurology, Kaohsiung Medical University Hospital; Kaohsiung Medical University, Kaohsiung, Taiwan. ${ }^{4} \mathrm{PhD}$ program in Translational Medicine, Kaohsiung Medical University and Academia Sinica, Taipei, Taiwan. ${ }^{5}$ Department of Physical Medicine and Rehabilitation, National Taiwan University Hospital, Bei-Hu Branch, Taipei, Taiwan. ${ }^{6}$ Department of Anesthesiology, National Taiwan University Hospital, Taipei, Taiwan. ${ }^{7}$ Taiwan Mouse Clinic - National Comprehensive Mouse Phenotyping and Drug Testing Center, Academia Sinica, Taipei, Taiwan.

Received: 7 September 2018 Accepted: 9 November 2018

Published online: 29 November 2018

\section{References}

1. Damaghi M, Wojtkowiak JW, Gillies RJ. pH sensing and regulation in cancer. Front Physiol. 2013;4:370.

2. Gregory NS, Brito RG, Fusaro MC, Sluka KA. ASIC3 is required for development of fatigue-induced hyperalgesia. Mol Neurobiol. 2016;53(2): 1020-230.

3. Hsieh WS, Kung CC, Huang SL, Lin SC, Sun WH. TDAG8, TRPV1, and ASIC3 involved in establishing hyperalgesic priming in experimental rheumatoid arthritis. Sci Rep. 2017;7:8870. 
4. Pan HL, Longhurst JC, Eisenach JC, Chen SR. Role of protons in activation of cardiac sympathetic C-fibre afferents during ischaemia in cats. J Physiol. 1999;518(3):857-66.

5. Woo YC, Park SS, Subieta AR, Brennan TJ. Changes in tissue $\mathrm{pH}$ and temperature after incision indicate acidosis may contribute to postoperative pain. Anesthesiology. 2004;101(2):468-75.

6. Lin $\mathrm{SH}$, Sun $\mathrm{WH}$, Chen CC. Genetic exploration of the roles of acid-sensing ion channels. Neuropharmacology. 2015;94:99-118.

7. Lin YW, Min MY, Lin CC, Chen WN, Wu WL, Yu HM, Chen CC. Identification and characterization of a subset of mouse sensory neurons that express acid-sensing ion channels. Neuroscience. 2008;151(2):544-57.

8. Deval $E$, Lingueglia E. Acid-sensing ion channels and nociception in the peripheral and central nervous systems. Neuropharmacology. 2015;94:49-57.

9. Issberner U, Reeh PW, Steen KH. Pain due to tissue acidosis: a mechanism for inflammatory and ischemic myalgia? Neurosci Lett. 1996;208(3):191-4.

10. Jones NG, Slater R, Cadiou H, McNaughton P, McMahon SB. Acid-induced pain and its modulation in himans. J Neurosci. 2004;24(48):10974-9.

11. Schwartz MG, Namer B, Reeh PW, Fischer MJM. TRPA1 and TRPV1 antagonists do not inhibit human acidosis-induced pain. J Pain. 2017;18(5):526-34.

12. Ugawa S, Ueda T, Ishida Y, Nishigaki M, Shibata $Y$, Shimada S. Amilorideblockable acid-sensing ion channels are leading acid sensors expressed in human nociceptors. J Clin Invest. 2002;110(8):1185-90.

13. Sun $\mathrm{WH}$, Chen $\mathrm{CC}$. Roles of proton-sensing receptors in the transition from acute to chronic pain. J Den Res. 2016;95(2):135-42.

14. Wu WL, Cheng CF, Sun WH, Wong CW, Chen CC. Targeting ASIC3 for pain, anxiety, and insulin resistance. Pharmacol Ther. 2012;134(2):127-38.

15. Chen WN, Lee CH, Lin SH, Wong CW, Sun WH, Wood JN, Chen CC. Roles of ASIC3, TRPV1, Nav1.8 in the transition from acute to chronic pain in a mouse model of fibromyalgia. Mol Pain. 2014;10:40.

16. Sluka KA, Price MP, Breese NM, Stucky CL, Wemmie JA, Welsh MJ. Chronic hyperalgesia induced by repeated acid injections in muscle is abolished by the loss of AISC3, but not ASIC1. Pain. 2003:106(3):229-39.

17. Kristal OA, Pidoplichko VI. Receptors for protons in the membrane of sensory neurons. Brain Res. 1981;214(1):150-4.

18. Kristal OA. The ASICs: signaling molecules? Modulators? Trends Neurosci. 2003;26(9):477-83.

19. Chen CC, Wong CW. Neurosensory mechanotransduction through acidsensing ion channels. J Cell Mol Med. 2013;17(3):337-49.

20. Fujii Y, Ozaki N, Taguchi T, Mizumura K, Furukawa K, Sugiura Y. TRP channels and ASICs mediate mechanical hyperalgesia in models of inflammatory muscle pain and delayed onset muscle soreness. Pain. 2008;140(2):292-304.

21. Ikoma A, Fartasch M, Heyer G, Miyachi Y, Handwerker H, Schmelz M. Painful stimuli evoke itch in patients with chronic pruritus: central sensitization for itch. Neurology. 2004;62(2):212-7.

22. Koo CC, Lin RS, Wang TG, Tsauo JY, Yang PC, Yen CT, Biswal S. Novel noxipoint therapy versus conventional physical therapy for chronic neck and shoulder pain: multicenter randomized controlled trials. Sci Rep. 2015;5: 16342.

23. Yin CS, Chae Y, Kang OS, Kim ST, Hahm DH, Park JY, Lee H, Park HJ. Deqi is double-faces: the acupuncture practitioner's and subject's perspective. Evid Based Complement Alternat Med. 2015;2015:635089.

24. Chen WN, Chen CC. Acid mediates a prolonged antinociception via substance $\mathrm{P}$ signaling in acid-induced chronic widespread pain. Mol Pain. 2014; 10:30.

25. Lin CCJ, Chen WN, Chen CJ, Lin YW, Zimmer A, Chen CC. An antinociceptive role for substance $P$ in acid-induced chronic muscle pain. Proc Natl Acad Sci U S A. 2012;109(2):E76-83.

26. Baumert $P$, Lake MJ, Stewart CE, Drust B. Genetic variation and exerciseinduced muscle damage: implications for athletic performance, injury and ageing. Eur J Appl Physiol. 2016;116(9):1595-625.

27. LaMotte RH, Dong $X$, Ringkamp M. Sensoty neurons and circuits mediating itch. Nat Rev Neurosci. 2014;15(1):19-31.

28. Ikoma A, Steinhoff M, Stander S, Yosipovitch G, Schmelz M. Neurobiology of itch. Nav Rev Neurosci. 2006;7(7):535-47.

29. Liu XY, Liu ZC, Sun YG, Ross M, Kim S, Tsai FF, Li QF, Jeffry J, Kim JY, Loh HH, Chen ZF. Unidirectional cross-activation of GRPR by MOR1D uncouples itch and analgesia induced by opioids. Cell. 2011;147(2):447-58.

30. Namer B, Reeh P. Scratching an itch. Nat Neurosci. 2013;16(2):117-8.

31. Lin SH, Steinhoff M, Ikoma A, Chang YC, Cheng YR, Kopparaju RC, Ishii S, Sun WH, Chen CC. Involvement of TRPV1 and TDAG8 in pruriception associated with noxious acidosis. J Invest Dermatol. 2017;137(1):170-8.
32. Lin SH, Cheng YR, Banks RW, Min MY, Bewick GS, Chen CC. Evidence for the involvement of ASIC3 in sensory mechanoransduction in proprioceptors. Nat Commun. 2016;7:11460.

33. Cheng YR, Jiang BY, Chen CC. Acid-sensing ion channels: dual function proteins for chemo-sensing and mechano-sensing. J Biomed Sci. 2018;25(1): 46.

34. Cummings NA, Nordby GL. Measurement of synovial fluid pH in normal and arthritic knee. Arthritis Rheum. 1966;9(1):47-56.

35. Abdelhamid RE, Sluka KA. ASICs mediate pain and inflammation in musculoskeletal diseases. Physiology. 2015;30(6):449-59.

36. Farr M, Garvey K, Bold AM, Kendall MJ, Bacon PA. Significance of the hydrogen ion concentration in synovial fluid in rheumatoid arthritis. Clin Exp Rheumatol. 1985:3(2):99-104.

37. Geborek P, Saxne T, Pettersson H, Wollheim FA. Synovial fluid acidosis correlates with radiological joint destruction in rheumatoid arthritis knee joints. J Rheumatol. 1989;16(4):468-72.

38. Ikeuchi M, Kolker SJ, Burnes LA, Walder RY, Sluka KA. Role of ASIC3 in the primary and secondary hyperalgesia produced by joint inflammation in mice. Pain. 2008;137(3):662-9.

39. Sluka KA, Rasmussen LA, Edgar MM, O'Donnell JM, Walder RY, Kolker SJ, Boyle DL, Firestein GS. Acid-sensing ion channel 3 deficiency increases inflammation but decreases pain behaviors in murine arthritis. Arthritis Rheum. 2013;65(5):1194-202.

40. Sun WH, Dai SP. Tackling pain associated with rheumatoid arthritis: protonsensing receptors. Adv Exp Med Biol. 2018;1099:49-64.

41. Wen J, Ouyang H, Yang R, Bo L, Zhang Y, Tang M, Liu Z. Malignancy dominated with rheumatic manifestations: a retrospective single-center analysis. Sci Rep. 2018;8(1):1786.

42. Lin JH, Hsieh YC, Chen YC, Wang Y, Chen CC, Chiang YH. Diagnostic accuracy of standardized qualitative sensory test in the detection of lumbar lateral stenosis involving the L5 nerve root. Sci Rep. 2017;7:10598.

43. Cheung K, Hume P, Maxwell L. Delayed onset muscle soreness: treatment strategies and performance factors. Sports Med. 2003;33(2):145-64.

44. Lin A. Writing Taiwanese: the development of modern written Taiwanese. In: Mair VH, editor. Sino-platonic papers, Vol. 89. Philadephia: Universsity of Pennsylvania; 1999. p. 17-25.

45. IASP. Task force on taxonomy. Merskey H, Bogduk N, editors. Seattle: IASP Press; 1994

46. Loeser JD. Perspectives on pain. In: Turner $P$, clinical pharmacology and therapeutics. London: MacMilan; 1980. p. 313-6.

47. Nemoto EM, Frinak S. Brian tissue $\mathrm{pH}$ after global brain ischemia and barbiturate loading in rats. Stroke. 1981;12(1):77-82.

48. Hulens M, Dankaerts W, Stalmans I, Somers A, Vansant G, Rasschaert R, Bruyninckx F. Fibromyalgia and unexplained widespread pain: the idiopathic cerebrospinal pressure dysregulation hypothesis. Med Hypotheses. 2018;110: 150-4.

49. Korsic M, Jugovic D, Kremzar B. Intracranial pressure and biochemical indicators of brain damage: follow-up study. Croat Med J. 2006;47(2):246-52

50. Hickey-Dwyer M, Gorey TF, O'Higgins N. Metabolic changes in small bowel ischaemia. Ir J Med Sci. 1984;153(7):233-7.

51. La Gamma EF, Krauss AN, Auld PA. Tissue surface pH monitoring during reduced blood flow: metabolic implications and sources of error. J Perinat Med. 1982:10(3):174-80.

52. Maurel S, Stankovic Stojanovic K, Avellino V, Girshovich A, Letavernier E, Grateau G, Baud L, Girot R, Lionnet F, Haymann JP. Prevalence and correlates of metabolic acidosis among patients with homozygous sickle cell disease. Clin J Am Soc Nephrol. 2014;9(4):648-53.

53. Okpala I, Tawil A. Management of pain in sickle-cell disease. J R Soc Med. 2002;95(9):456-8.

54. Kofoed $\mathrm{H}$. Synovitis causes hypoxia and acidity in synovial fluid and subchondral bone. Injury. 1986;17(6):391-4.

55. Edlow DQ, Sheldon WH. The pH of inflammatory exudates. Proc Soc Exp Biol Med. 1971;137(4):1328-32.

56. Ganesh K, Sharma RN, Varghese J, Pillai MG. A profile of metabolic acidosis in patients with sepsis in an intensive care unit setting. Int J Crit IIn Inj Sci. 2016:6(4):178-81.

57. Hu JJ, Kao CL, Lee PI, Chen CM, Lee CY, Lu CY, Huang LM. Clinical features of influenza $\mathrm{a}$ and $\mathrm{B}$ in children and association with myositis. J Microbiol Immunol Infect. 2004;37(2):95-8.

58. Rodriguez-Gutierrez R, Camara-Lemarroy CR, Quintanilla-Flores DL, GonzalezMoreno El, Gonzalez-Chavez JM, Lavalle-Gonzlez FJ, Gonzalez-Gonzalez JG, 
Caballero AE. Severe ketoacidosis $(\mathrm{pH} \leq 6.9)$ in type 2 diabetes: more frequent and less ominous than previously thought. Biomed Res Int. 2015; 2015:134780.

59. Negi A, Rhys-Dillon C, Camilleri JP. A case of distal tubular acidosis (type 1) presenting with musculoskeletal pain. Rheumatology. 2004;43(6):809-10.

60. Kikuta J, Wada Y, Kowada T, Wang Z, Sun-Wada GH, Nishiyama I, Mizukami S, Maiya N, Yasuda H, Kumanogoh A, Kikuchi K, Germain RN, Ishii M.

Dynamic visualization of RANKL and Th17-mediated osteoclast function. J

Clin Invest. 2013;123(2):866-73.

Ready to submit your research? Choose BMC and benefit from:

- fast, convenient online submission

- thorough peer review by experienced researchers in your field

- rapid publication on acceptance

- support for research data, including large and complex data types

- gold Open Access which fosters wider collaboration and increased citations

- maximum visibility for your research: over $100 \mathrm{M}$ website views per year

At $\mathrm{BMC}$, research is always in progress.

Learn more biomedcentral.com/submissions 